\title{
AN ASSESSMENT OF DISINCENTIVE POLICY ON SLOT ALLOCATION SYSTEM IN INDONESIAN AIRPORTS
}

\author{
Danang Parikesit ${ }^{1}$ \\ Faculty of Engineeering, Universitas Gadjah Mada, Indonesia \\ Safrilah $^{2}$ \\ Civil Engineering Department, Universitas Bakrie, Indonesia \\ Yusa C. Permana ${ }^{3}$ \\ The Indonesia Transportation Society, Jakarta, Indonesia
}

\begin{abstract}
Indonesian airports have been experiencing significant air traffic growth and are unable to cope with the increasing air passenger demand. There is an urgent need for an effective slot allocation strategy to manage the demand for airport capacity. This paper conducts a case study to examine the possibility of managing slot time allocation to maximize runways capacity by analyzing disincentive strategy in balancing the usage of runways with Capacity Restraint and Demand Balanced approach. The research found that airlines willing to use slot time at the most demanded time interval should pay an additional $6.57 \%$ (CR approach) from total revenue gained by the government from slot sector and 6.55\% (DB approach). The additional cost for less demanded slot time interval is only $0.09 \%$ (in both $\mathrm{CR}$ and $\mathrm{DB}$ approaches). Findings from this study should be considered as an initial step toward educating policy makers and airport authorities with the aims to creating better mechanism in Indonesia's airspace market.
\end{abstract}

Keywords: airport capacity, slot time allocation, slot pricing, disincentive strategy, slot auction.

\footnotetext{
${ }^{1}$ Faculty of Engineeering, Universitas Gadjah Mada, Jalan Grafika 2 Yogyakarta, Indonesia Phone number +6287838925688, Email: dparikesit@ugm.ac.id; parikesit.danang@gmail.com

${ }^{2}$ Civil Engineering Department, Universitas Bakrie, JI. HR Rasuna Said Jakarta, Indonesia Email: safrilah@bakrie.ac.id

${ }^{3}$ The Indonesia Transportation Society, Jakarta, Indonesia

Email: yusacahya@gmail.com
} 


\section{THE NEEDS FOR EXPANDING THE INDONESIA'S AIRPORT CAPACITIES}

In the last 5 years, the number of domestic and international flights in Indonesia is increasing up to $36.94 \%$ and $29,19 \%$, respectively, while the increase of passenger's number is $70.72 \%$ in domestic and $39.06 \%$ in international flight (The Directorate General of Air Transportation). The reliability in travel time, constant travel frequency, the emergence of low cost air carriers in line with competitive in ticket price combined with highly dynamic economic activities in Indonesia led to the significant growth of domestic and international flight as well as the number of passengers as shown in Table 1 and Table 2.

Table 1: Indonesia's Yearly Domestic Flights and Passengers Number

\begin{tabular}{lll}
\hline YEAR & NUMBER OF FLIGHTS & NUMBER OF PASSENGERS \\
\hline 2009 & 812,231 & $70,934,675$ \\
2010 & 950,153 & $90,596,305$ \\
2011 & $1,064,373$ & $117,827,572$ \\
2012 & $1,008,111$ & $124,590,275$ \\
2013 & $1,112,237$ & $121,103,078$ \\
\hline
\end{tabular}

Table 2: Indonesia's Yearly International Flights and Passengers Number

\begin{tabular}{lll}
\hline YEAR & NUMBER OF FLIGHTS & NUMBER OF PASSENGERS \\
\hline 2009 & 105,785 & $13,350,430$ \\
2010 & 142,057 & $18,719,784$ \\
2011 & 143,383 & $20,589,765$ \\
2012 & 167,038 & $23,461,775$ \\
2013 & 136,668 & $18,565,598$ \\
\hline
\end{tabular}

Aware with the statistical data that stated promising number of air transportation's passengers in the future, the Ministry of Transportation (MoT) in their 2010-2014 strategic plan formulates a strategy to expand air transportation capacity. The strategy was manifested by forming IASM (Indonesian Airport Slot Management) to improve flight's safety and security, optimizing airport capacity and facilities, slot time standardization refers to IATA's regulation and cost efficiency, extending runway's length and width to meet the landing and take-off needs of larger aircraft types, 
operating additional terminals and airports in dealing with increasing demand in air transportation and improving airport capacity and also maximizing operational hours for busy airports.

Some efforts of MoT in realizing the principal strategies listed above reflected in the following points:

a) Juanda Airport in East Java operates the second terminal with the aim of capacity and performance improvement;

b) Mutiara SIS AlJufri Airport in Palu with approximately $138 \%$ increase in passenger's movement from 2009 until 2013 operates a renovated terminal;

c) Additional slot time in several airports. Sultan Mahmud Badaruddin II airport in Palembang, Sultan Syarif Kasim II airport in Pekanbaru, Supadio airport in Pontianak, and Minangkabau airport in Padang extends the operating hours until 24.00;

d) Additional 270 m length for Iskandar Airport's runway in Pangkalan Bun;

e) Halim Perdanakusuma airport was re-activated to serve regular flights in order to help reducing high number of aircraft movements in Sukarno Hatta Airport;

f) Revitalization in both air side and land side in Sukarno Hatta Airport.

Sukarno-Hatta International Airport (SHIA) or known as Cengkareng (CGK) by the locals is Indonesia's main gateway into the world. SHIA has two effective runways to serve passenger flights, runway $07 R / 25 \mathrm{~L}$ and $07 \mathrm{~L} / 25 \mathrm{R}$ that operated 24 hours a day (runway utilization shown in Figure 1). In June 2013 (latest data from ministry of transportation), 17,294 aircrafts which carrying 2,764,786 passengers were arrived and 17,036 aircrafts (carrying 2,462,722 passengers) departed from SHIA.

With a significant growth in aircraft and passenger movement, soon the existing runways in SHIA will be overloaded during peak hour therefore there is necessity to optimize the current slot is become an urgent decision.

The paper will address first step to one main option to maximize the use of current slot, which is an auction. Auction is discussed as an effective and fair solution to allocate and re-allocate slots and hence generating optimum capacity as efficient as slot trading regime. (Brueckner[1] and econ report[2]). For the preliminary study to define the mechanism of the auction, the bidding price is considered as a serious issue and need to be determined carefully. By learning on the actual movements, the paper will trying to specify not only the equitable range for bidding price, but also the prospect of which slot decided to be auctioned by distributing demand for the air transportation. 
Fig. 1 Soekarno Hatta International Airport Ultilization
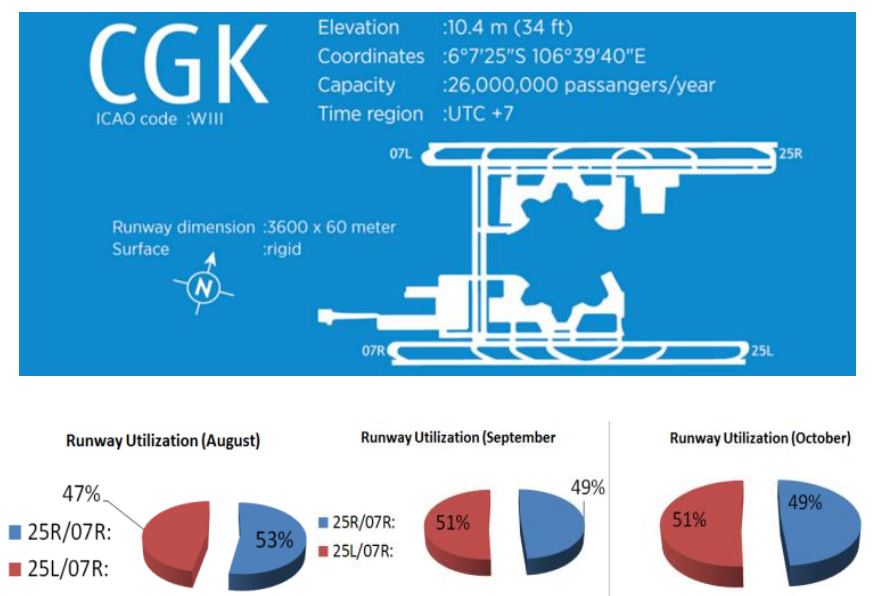

Source: http://soekarnohatta-airport.co.id (modified)

\section{CURRENT SLOT TIME ALLOCATION PROCEDURE IN INDONESIA}

The grandfather rights, the rights where the airline posesses the right for slot time they previously held oin the previous year season, slot has been for long time became one of internationally agreed major clauses in the airport slot allocation system. The Indonesian air transportation regulation which adopt the international standard in turn also adopt such system for Indonesian slot allocation system.

The application of grandfather rights itself may help to ease and simplify the slot allocation system in many airports globally. But the system itself is not a perfect solution. In congested airport the application of such system cause some questions. As is highlighted by Starkie et al[3] the application "property rights" over slot time "Can put the airline as the slot holder a substantial competitive advantage over their rivals". Another issue over the grandfather rights is the inneficiency over the slot usage. Castelli[4] argue in their paper that the excercising of grandfather right "can inducing airlines to use slots ineffciently for not loosing them." Further Castelli also argue that further application of the system will cause barrier for the market, causing market immobility and prevent a fair competition among the airlines which further cause the slot time as a scarce resouce become innefficiently used .

The Indonesian Airport Slot Allocation system is highly regulated by the government with the private sector only served as the airline operators. The slot allocation in Indonesia is regulated by Directorate General of Air Transportation, Indonesian Ministry of Transportation. The Indonesia Airport Slot Management or IASM is the body under Directorate General of Air Transportation which 
directly control slot allocation system for domestic flight in Indonesia. For the International flight, the task is still hold by the national flag Carrier, Garuda Indonesia.

The latest regulation concerning the slot allocation system is issued by the Director General of Air Transportation in the form of KP Num. 280 year 2015 [5]which in it covers major update in slot time allocation regulation based on international standard and the previously issued KP Num. 401,402 and 569 Year 2011 concerning about the regulation on slot coordinator.

As with international system, the Indonesian slot allocation system is based on 6 monthly slot allocation system or the "season" system. The grandfather rights in Indonesia applies to all slot time already allocated in the previous years season. The airline which held the rights for the respective slot must be able to must operates within the allocated slot time for at least $80 \%$ throughout the season periods ( $80-20$ rule). If by case the airline failed to meet the $80 \%$ standard or by their own decission they wish to release their rights on the allocated slot then their rights for the allocated slot can be revoked (use it or lose it), the detail of slot management on Figure 2. The unallocated or released slot will be available for new applicant based on first come first served system.

In Indonesia itself there are eight airports declared as slot coordinated airport and thus the slot regulation is to be under the IASM. These airports are:

1. Kuala Namu International Airport, North Sumatera

2. Sultan Mahmud Badaruddin II, South Sumatera

3. Soekarno-Hatta International Airport, Jakarta

4. Sepinggan International Airport, East Kalimantan

5. Juanda International Airport, East Java

6. I Gusti Ngurah Rai International Airport, Bali.

7. Sultan Hasanuddin International Airport, South Sulawesi

8. Sentani International Airport, Papua. 
Fig. 2 Slot Time Management in Indonesia (Based on KP 280 Year 2015)

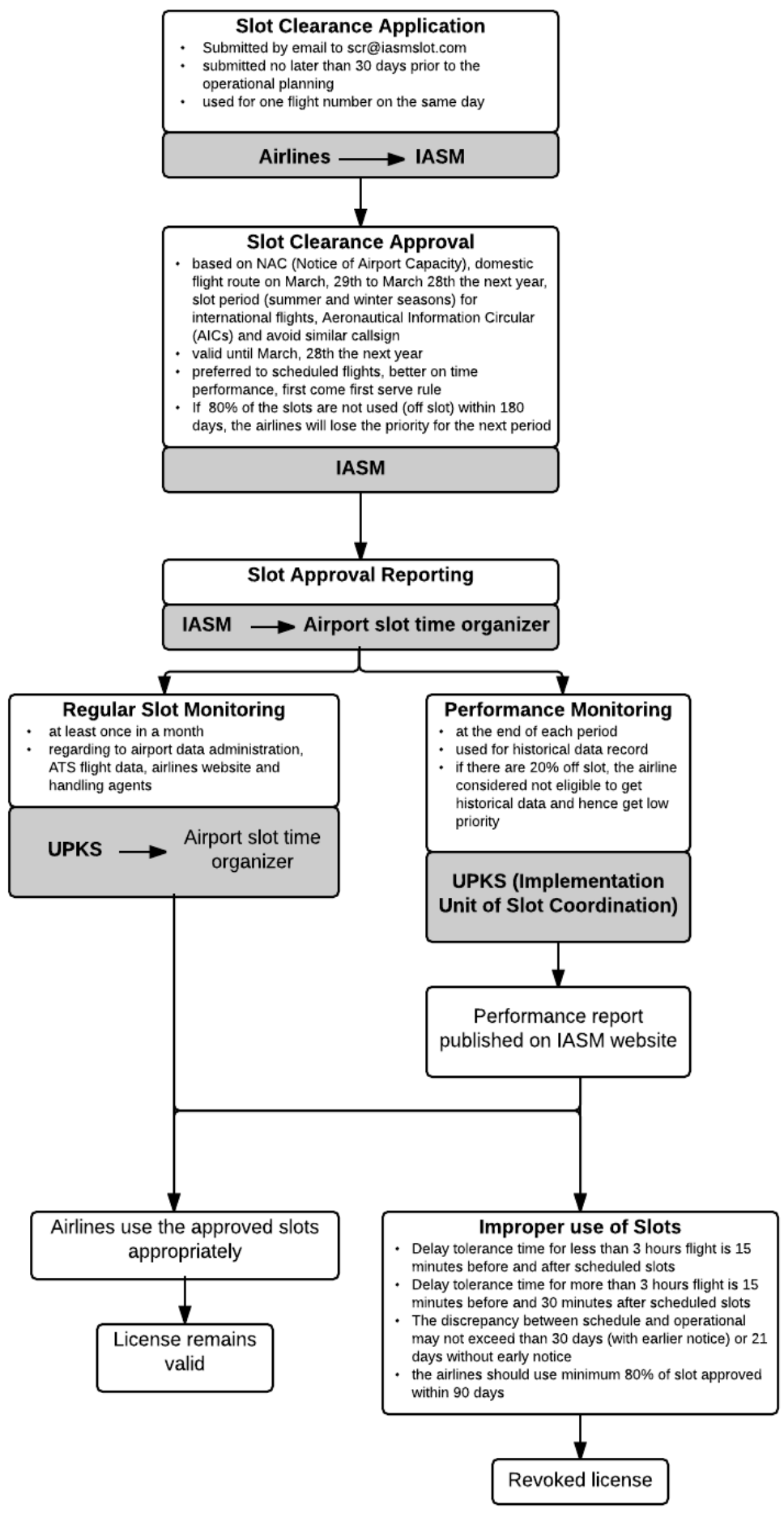




\section{THOUGHT TO OPTIMIZE THE USE OF SLOT TIME ALLOCATION}

With the current procedure, infrastructure and their high demand, SHIA, as with many other airport faces critical air traffic and slot allocation problems, still require the additional slot or else, maximizing the capacity by managing the existing slot better. The pricing strategies seems promising and fair, those airlines who wants to use peak hours should pay much more than other who willing to use off-peak hours and generates well distributed demand. The concept of price itself is as explained by Weber[6] is the concept of trades of goods and services between two economics agents. The prices of the products itself may be determined either by their real value or nominal value. In relation to this conditions the slot itself became an important product as they are very important for airline operation but their availability is restricted by the capacity of the airport and airport networks itself.

Polsby[7] explains that there are multiple potential benefits resulted from the slot time pricing . Some of those are the incentive for airline to spread their schedule, less congested airport during the usual peak hour, and the ability of fund gathering to improve the physical capacity of the airport itself. The pricing mechanisim itself can be in the form of peak hour charge during operation or slot auction during the slot allocation process. The implementation of the scheme sholud be carried out in careful manners as there are multiple potential conflicts that may arise from the peak hour charging.

\section{LESSONS LEARNED FROM INDONESIAN TELECOMMUNICATION SECTOR}

In Indonesia, the demand for telecommunication sector is high and hence resulting enormous potential in secondary market for its radio frequency spectrum [8]. One of the famous telecommunication frequencies is $2.1 \mathrm{GHz}$ frequency (known well as 3G frequencies) and the government decided to conduct auction as an effort in structuring the use of $2.1 \mathrm{GHz}$ frequency. The decree was issued as a guideline in radio frequency spectrum auction and provide general rule of the auction, detail frequency auctioned, permit fee, auction procedure and decision-making[9]. In relation with tariff issues, the decree state that the permit fee value determined greater than reserve price for the auction while the permit fee itself consist of two components, upfront fee and BHP (concession fee). By understanding the steps to calculate the BHP, the government will be able to set the reserve price as well and get the least or minimum revenue from each block of $2.1 \mathrm{GHz}$ frequency. 
According to the decree of Minister of Communication and Information Technology Num. 7 year 2009[10] amended to Num. 76 year 2010[11] about non-tax revenue in communication and information technology department and Num. 24 year 2010[12] which is a refinement of previous decree Num. 19 year 2005[13] about tariff guidelines on non-tax revenue, in every utilization of radio frequency spectrum required to pay $\mathrm{BHP}$, as the embodiment of economic value of radio frequency, in advance every year, sixty days after payment notification letter (SPP) issued, otherwise the application will be revoked.

Tariff/BHP calculated per frequency used, per station, per location per year and based on formula given below:

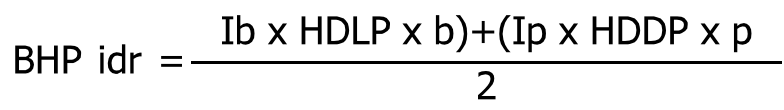

$\mathrm{Ib}=$ bandwidth occupied fare index

HDLP=bandwidth base fare

$\mathrm{b}=$ Bandwidth $\mathrm{kHz}$

$I p=$ frequency emittance fare index

HDDP=emittance base fare

$\mathrm{P}=$ emittance $(\mathrm{EIRP})[\mathrm{dBm}]$

Zoning for frequency listed on decree of Minister of Communication and Information Technology Num. 19 year 2005, while the value of HDLP and HDDP were determined on decree of Minister of Communication and Information Technology Num. 76 year 2010. The brief comparison between HDLP and HDDP base price listed on Table 3 and vary depending on the location determined by the government. 
Table 3 HDLP and HDDP Base Price based on Location

\begin{tabular}{|c|c|c|c|c|}
\hline PROVINCE & ZONE & SEGMENTATION & $\begin{array}{c}\text { HDLP } \\
(\mathrm{RP} / \mathrm{KHZ})\end{array}$ & $\begin{array}{c}\text { HDDP } \\
(\mathrm{RP} / \mathrm{KHZ})\end{array}$ \\
\hline \multirow{8}{*}{$\begin{array}{l}\text { DKI } \\
\text { Jakarta }\end{array}$} & \multirow[t]{8}{*}{1} & VLF: $9-30 \mathrm{KHz}$ & 20.961 & 191.629 \\
\hline & & LF: $30-300 \mathrm{KHz}$ & 15.725 & 142.844 \\
\hline & & MF: $300-3000 \mathrm{KHz}$ & 15.249 & 140.403 \\
\hline & & HF: $3-30 \mathrm{MHz}$ & 14.581 & 135.353 \\
\hline & & VHF: $30-300 \mathrm{MHz}$ & 12.888 & 119.665 \\
\hline & & UHF: $300-3000 \mathrm{MHz}$ & 11.772 & 109.481 \\
\hline & & SHF: $3-30 \mathrm{GHz}$ & 9.681 & 89.364 \\
\hline & & EHF: $30-275 \mathrm{GHz}$ & 6.101 & 54.188 \\
\hline \multirow{8}{*}{ Balikpapan } & \multirow[t]{8}{*}{2} & VLF: $9-30 \mathrm{KHz}$ & 16.769 & 153.303 \\
\hline & & LF: $30-300 \mathrm{KHz}$ & 12.572 & 114.275 \\
\hline & & MF: $300-3000 \mathrm{KHz}$ & 12.199 & 112.322 \\
\hline & & HF: $3-30 \mathrm{MHz}$ & 11.665 & 108.282 \\
\hline & & VHF: $30-300 \mathrm{MHz}$ & 10.310 & 95.732 \\
\hline & & UHF: $300-3000 \mathrm{MHz}$ & 9.418 & 87.585 \\
\hline & & SHF: $3-30 \mathrm{GHz}$ & 7.745 & 71.491 \\
\hline & & EHF: $30-275 \mathrm{GHz}$ & 4.881 & 43.350 \\
\hline \multirow[t]{8}{*}{ Padang } & \multirow[t]{8}{*}{3} & VLF: $9-30 \mathrm{KHz}$ & 12.576 & 114.977 \\
\hline & & LF: $30-300 \mathrm{KHz}$ & 9.429 & 85.707 \\
\hline & & MF: $300-3000 \mathrm{KHz}$ & 9.149 & 84.242 \\
\hline & & HF: $3-30 \mathrm{MHz}$ & 8.749 & 81.212 \\
\hline & & VHF: $30-300 \mathrm{MHz}$ & 7.733 & 71.799 \\
\hline & & UHF: $300-3000 \mathrm{MHz}$ & 7.063 & 65.688 \\
\hline & & SHF: $3-30 \mathrm{GHz}$ & 5.809 & 53.618 \\
\hline & & EHF: $30-275 \mathrm{GHz}$ & 3.661 & 32.513 \\
\hline \multirow[t]{8}{*}{ Bengkulu } & \multirow[t]{8}{*}{4} & VLF: $9-30 \mathrm{KHz}$ & 8.384 & 76.652 \\
\hline & & LF: $30-300 \mathrm{KHz}$ & 6.286 & 57.138 \\
\hline & & MF: $300-3000 \mathrm{KHz}$ & 6.099 & 56.161 \\
\hline & & HF: $3-30 \mathrm{MHz}$ & 5.832 & 54.141 \\
\hline & & VHF: $30-300 \mathrm{MHz}$ & 5.155 & 47.866 \\
\hline & & UHF: $300-3000 \mathrm{MHz}$ & 4.709 & 43.792 \\
\hline & & SHF: $3-30 \mathrm{GHz}$ & 3.873 & 35.745 \\
\hline & & EHF: $30-275 \mathrm{GHz}$ & 2.440 & 21.675 \\
\hline \multirow[t]{8}{*}{ Gorontalo } & \multirow[t]{8}{*}{5} & VLF: $9-30 \mathrm{KHz}$ & 4.192 & 38.326 \\
\hline & & LF: $30-300 \mathrm{KHz}$ & 3.143 & 28.569 \\
\hline & & MF: $300-3000 \mathrm{KHz}$ & 3.050 & 28.081 \\
\hline & & HF: $3-30 \mathrm{MHz}$ & 2.916 & 27.071 \\
\hline & & VHF: $30-300 \mathrm{MHz}$ & 2.578 & 23.933 \\
\hline & & UHF: $300-3000 \mathrm{MHz}$ & 2.354 & 21.896 \\
\hline & & SHF: $3-30 \mathrm{GHz}$ & 1.936 & 17.873 \\
\hline & & EHF: $30-275 \mathrm{GHz}$ & 1.220 & 10.838 \\
\hline
\end{tabular}

To summarize, the value of reserve price in $2.1 \mathrm{GHz}$ frequency's auction was based on the highest demand on it and determined by divided the market into zones with each price range. 


\section{SLOT CAPACITY OPTIMIZATION SCENARIO}

The research is based on August-October 2010 flight movements data on Soekarno-Hatta International Airport. The purpose of this research for researching and testing the feasibility of slot auctioning in Soekarno-Hatta airport. The result of this research may not be used directly for the application of slot auctioning but can be used as the baseline for further research and development of slot auctioning system either in Soekarno-Hatta or other congested airport.

The data used in this research consist of 24 hours flight movement based on slot clearance and actual landing and take off activities in Soekarno-Hatta airport. The data that are used are flight clearance data with assumption that actual landing and take off time is the result inter-reaction with inconsistent external factors that are not significantly affect the implementation of slot time.

The data is first sorted into one month-daily data with each day consist of twenty-four hourly interval starting from 00.00-00.59 until 23.00-23.59. This resulted with each month (August, September and October) having their own data set. The pattern of the actual data is however rather inconsistent, with some intervals in one month period having a normal, bi-normal or skew distribution. For the development of the equation, it is assumed that the data is having a normal distribution.

Based on the assumption that the data having normal distribution then the pattern or average daily movement in Soekarno hatta Airport can be retrieved. Paired sample test then carried out to find the correlation among the monthly data. Paired samples $t$ test on data results are as follow:

a) The population correlation $(\rho)$ is different from $0 p=0.00$, and it is able to reveal a statistically reliable difference between the mean number of August $(M=34.23, s=21)$ and September $(M=41.66, s=24.50)$ Landing and Take Off Movements, $t(23)=8.144, p=.00, a=$ .05 .

b) The population correlation ( $\rho$ ) is different from $0 p=0.00$ and it is able to reveal a statistically reliable difference between the mean number of September $(M=41.66, s=24.50)$ and October $(\mathrm{M}=40.37, \mathrm{~s}=23.22)$ Landing and Take Off Movements, $t(23)=3.231, p=.04, \mathrm{a}=$ .05 .

c) The population correlation ( $\rho$ ) is different from $0 p=0.00$ and it is able to reveal a statistically reliable difference between the mean number of August $(M=34.23, s=21)$ and October ( $M=40.37, s=23.22)$ Landing and Take Off Movements, $t(23)=9.044, p=.00, a=.05$.

Based on this result, the 3 month data can be treated as a single data for the next analysis. The result of data analysis can be seen in Figure 3. 


\section{Fig. 3 Actual Average 3 Months Landing-Take Off Movements}

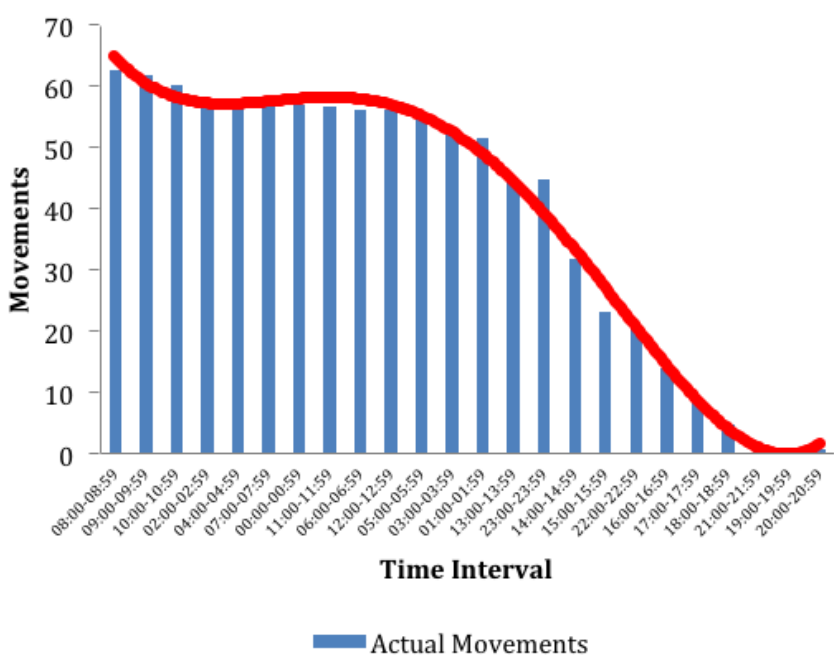

Figure 3 represents average hourly movements for slot time interval represented by the number of aircraft movements within one hour interval. The data shows that between August-October 2010 the highest demand happened in time intervals 08.00-08.59 followed by time interval 09.00-09.59 and 10.00-10.59. The lowest demand level occured in the 19.00-19.59 and 20.00-20.59 time interval.

The next phase af analysis is to determine the price of aircraft movement according to available data. For this research there are two approaches to be used. The first is based on the Capacity Restraint (CR) of the airport and the second is based on the Balanced Demand (BD) approach.

The next analysis conducted with the following conditions:

a) Polynomial equation is the best fit for this data set, then it will be used for further analysis. The equation for demand curve in figure 2 is $f x=f(x)=0,0024236 x^{4}-0,1149683 x^{3}+1,58436926 x^{2}-8,2256893 x+71,616609$ with $R^{2}=0.9936$.

b) represents price to pay with $x$ represents slot time interval.

C) $\quad x=0$ represents the lower end of the first interval and $\mathrm{x}=24$ represents the higher end of last interval represents total revenue from slot allocation $(A)$.

d) The integration of $y=f(x)$ from $x=0$ to $x=24$ (total area) represents total revenue from 24 hours movement (set by the government which aims to be earned from slot allocation system). 


\subsection{Capacity Restraint (CR) Approach}

The idea to improve runways capacity is to distribute the use of slots into less demanded slots by giving disincentive to airlines, which tends to favor high demand slot periods. Setting the baseline is needed to determine which time intervals should 'share' their movements. The actual design capacity for Soekarno Hatta airport is actually 82 aircraft movements per hour for two runway. In the application, due to safety and technical consideration, the capacity is still set at 52 in 2013 and increased into 64 in 2014. There is a target to further increase the capacity into 72 movements per hour. For this research, the airport capacity is set at 2012-2013 treshold, which is 52 aircraft movements per hour and plotted into existing chart (Figure 4). This is considering the fact that data being used is 2010 thus the most recent capacity should not be used.

Fig. 4 Capacity Restraint Approach

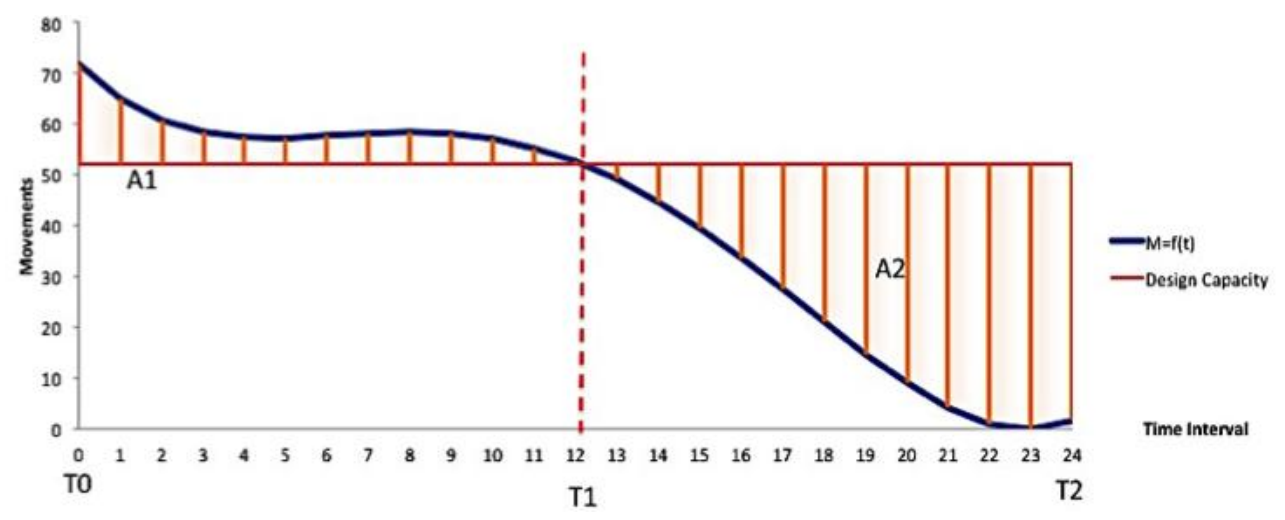

In this approach, it is assumed that :

- T0 : Begining of time interval-1, which is equal to zero.

- $\quad$ T1 : Intercept point between movements $f(t)$ and design capacity. Derived by setting $f(t)=52$ (designed capacity).

- T2 : End of interval-24 which is equal to 24.

- A1 : Revenue from aircraft movements above designed capacity

- A2 : Gap revenue of aircraft movements below designed capacity

- D : Designed Capacity

The price can then be calculated based on the following equation

a) $\quad \mathrm{A} 1 . \mathrm{P} 1=\mathrm{A} 2 . \mathrm{P} 2$

b) Basic movement revenue $=(\mathrm{TO}-\mathrm{T} 1) \mathrm{D}$

c) Movement price above designed capacity $=A 1 / \Sigma M$ for T0 $-\mathrm{T} 1$

d) Movement price below designed capacity $=\mathrm{A} 2 / \Sigma \mathrm{M}$ for $\mathrm{T} 1-\mathrm{T} 2$ 


$$
{ }_{0}^{\mathrm{T} 1} \mathrm{M}-\mathrm{D} d \mathrm{dT} . \mathrm{P} 1={ }_{\mathrm{T} 1}^{\mathrm{T} 2} \mathrm{D}-\mathrm{M} \mathrm{dT} \mathrm{P} 2 \ldots \ldots . .(1)
$$

The calculation results for Capacity Restraint pricing are as followed:

- Designed Capacity (D) : 52 movements

- $\quad \mathrm{T} 1$ : interval 12.2

- $\quad$ Basic Movement revenue (T0-T1).D : 634.556 unit area

- $A 1$ : 80.4 unit area

- $\mathrm{A} 2$ : 354.1 unit area

- P1 : $4.4 \mathrm{P} 2$

- Movement price above designed capacity : 0.114 unit area/movement

- Movement price below designed capacity : 1.093 unit area/movement

- $\quad$ Basic Movement price : 0.903 unit area/movement

\subsection{Balanced Demand (BD) Approach}

The balanced demand approach comes with aims to prioritize demand balancing. The analysis set up based on the idea that area above balanced demand curve is equal to an area below the balanced demand (and also bounded by demand curve on first quadrant). Wherever those two curves intersect, we called it as balancing point which we believe is the proper starting line to the next steps of analysis.

Fig. 5 Balance Demand Approach

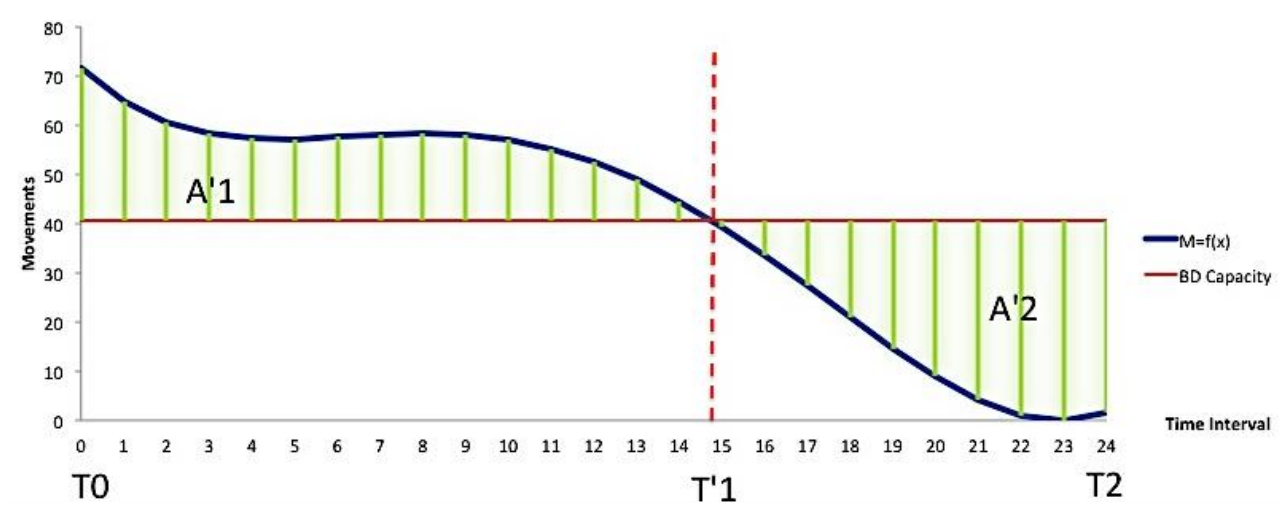

In this approach, it is assumed that :

- T0 : Beginning of time interval-1, which is equal to zero

- $\quad T^{\prime} 1 \quad$ : Intercept point between movements $\mathrm{f}(\mathrm{t})$ and balanced demand capacity.

- $\quad \mathrm{T2} \quad$ : End of interval-24 which is equal to 24

- $\quad \mathrm{A}^{\prime} 1 \quad$ : Revenue of aircraft movements above BD capacity

- $\quad A^{\prime 2} \quad$ : Gap revenue of aircraft movements below BD capacity 
- $\quad$ D' $\quad$ : Balanced Demand Capacity

The price can then be calculated based on the following equation
a) $\quad \mathrm{A}^{\prime} 1=\mathrm{A}^{\prime} 2$
b) Basic movement revenue $=(\mathrm{T} 0-\mathrm{T} 1) \cdot \mathrm{D}^{\prime}$
C) Movement price above balanced demand $=A^{\prime} 1 / \Sigma M$ for $T 0-T 1$
d) Movement price below balanced demand =

$$
\begin{aligned}
& A^{\prime} 2 / \Sigma M \text { for } T 1-T 2 \\
& T^{T^{\prime} 1} M-D^{\prime} d T={ }_{T^{\prime} 1}^{T^{\prime} 2} D^{\prime}-M d T
\end{aligned}
$$

The calculation results for Balanced Demand pricing are as followed :

- $\quad$ Balanced Demand Capacity (D') : 40.6 movements

- $\quad \mathrm{T}^{\prime} 1 \quad$ : interval 14.78

- $\quad$ Basic Movement revenue (T0-T'1).D' : 600.056 unit area

- $\quad \mathrm{A}^{\prime} 1=\mathrm{A}^{\prime} 2 \quad: 235.49$ unit area

- $\quad \mathrm{P} 1 \quad: \mathrm{P} 2$

- Movement price above designed capacity : 0.286 unit area/movement

- Movement price below designed capacity : 1.195 unit area/movement

Basic Movement price : 0.728 unit area/movement 


\section{IMPROVING RUNWAYS CAPACITY: DISINCENTIVE PRICING STRATEGY}

As one of the main problems in the Soekarno Hatta airport is the air traffic congestion due to the tendency of the airline to operate at "peak hour period", some form of regulation is needed to control this tendency. One of which is the disincentive system. To calculate the disincentive this research are using the runway capacity as the baseline.

Based on the previous analysis there are two baseline that will be used in this analysis, the Designed Capacity and Balanced Demand baseline. To calculate the price some assumtion is made regarding the time interval located in the intersection point between the demand and capacity graph which is at $T 1=12.2$ and $T^{\prime} 1=14.78$. In this case it is assumed that the disincentive will be applied for both interval-13 $(T=13)$ in the CR scenario and interval $-15(T=15)$ in the BD scenario .

For the disincentive, the applied price will be the movement price above capacity and added in it the basic price. The calculation result can be presented in Table 4.

Table 4 Price Comparison between CR and BD Approach

\begin{tabular}{|c|c|c|c|c|c|}
\hline \multirow[b]{2}{*}{ INTERVAL } & \multirow[b]{2}{*}{ ACTUAL } & \multicolumn{2}{|c|}{$\begin{array}{c}\text { FINAL PRICE } \\
\text { (IN UNIT AREA) }\end{array}$} & \multicolumn{2}{|c|}{$\begin{array}{c}\text { PERCENTAGE } \\
\text { COMPARED TO A }\end{array}$} \\
\hline & & $\mathrm{CR}$ & $B D$ & CR & $B D$ \\
\hline NUMBER & MOVEMENT & SCENARIO & SCENARIO & SCENARIO & SCENARIO \\
\hline 1 & 62,77 & 63,83 & 63,63 & $6,57 \%$ & $6,55 \%$ \\
\hline 2 & 61,91 & 62,96 & 62,76 & $6,48 \%$ & $6,46 \%$ \\
\hline 3 & 60,27 & 61,28 & 61,10 & $6,31 \%$ & $6,29 \%$ \\
\hline 4 & 57,96 & 58,94 & 58,76 & $6,07 \%$ & $6,05 \%$ \\
\hline 5 & 57,78 & 58,75 & 58,57 & $6,05 \%$ & $6,03 \%$ \\
\hline 6 & 57,20 & 58,16 & 57,98 & $5,99 \%$ & $5,97 \%$ \\
\hline 7 & 57,15 & 58,11 & 57,93 & $5,98 \%$ & $5,97 \%$ \\
\hline 8 & 56,80 & 57,76 & 57,58 & $5,95 \%$ & $5,93 \%$ \\
\hline 9 & 56,16 & 57,11 & 56,93 & $5,88 \%$ & $5,86 \%$ \\
\hline 10 & 56,13 & 57,08 & 56,90 & $5,88 \%$ & $5,86 \%$ \\
\hline 11 & 55,55 & 56,49 & 56,31 & $5,82 \%$ & $5,80 \%$ \\
\hline 12 & 52,98 & 53,87 & 53,70 & $5,55 \%$ & $5,53 \%$ \\
\hline 13 & 51,60 & 52,47 & 52,31 & $5,40 \%$ & $5,39 \%$ \\
\hline 14 & 44,90 & 49,09 & 45,52 & $5,05 \%$ & $4,69 \%$ \\
\hline 15 & 44,89 & 49,08 & 45,51 & $5,05 \%$ & $4,69 \%$ \\
\hline 16 & 31,87 & 34,84 & 38,09 & $3,59 \%$ & $3,92 \%$ \\
\hline 17 & 23,15 & 25,30 & 27,66 & $2,61 \%$ & $2,85 \%$ \\
\hline 18 & 20,40 & 22,30 & 24,38 & $2,30 \%$ & $2,51 \%$ \\
\hline 19 & 13,96 & 15,27 & 16,69 & $1,57 \%$ & $1,72 \%$ \\
\hline 20 & 8,65 & 9,45 & 10,33 & $0,97 \%$ & $1,06 \%$ \\
\hline 21 & 4,77 & 5,21 & 5,70 & $0,54 \%$ & $0,59 \%$ \\
\hline
\end{tabular}




\begin{tabular}{|c|c|c|c|c|c|}
\hline \multirow[b]{2}{*}{ INTERVAL } & \multirow[b]{2}{*}{ ACTUAL } & \multicolumn{2}{|c|}{$\begin{array}{c}\text { FINAL PRICE } \\
\text { (IN UNIT AREA) }\end{array}$} & \multicolumn{2}{|c|}{$\begin{array}{c}\text { PERCENTAGE } \\
\text { COMPARED TO A }\end{array}$} \\
\hline & & CR & $\mathrm{BD}$ & $\mathrm{CR}$ & $\mathrm{BD}$ \\
\hline NUMBER & MOVEMENT & SCENARIO & SCENARIO & SCENARIO & SCENARIO \\
\hline 22 & 1,70 & 1,85 & 2,03 & $0,19 \%$ & $0,21 \%$ \\
\hline 23 & 1,01 & 1,11 & 1,21 & $0,11 \%$ & $0,12 \%$ \\
\hline 24 & 0,77 & 0,84 & 0,92 & $0,09 \%$ & $0,09 \%$ \\
\hline
\end{tabular}

The pricing analysis above is sorted based on number of interval ( $1^{\text {st }}$ to $24^{\text {th }}$ interval), changing number of interval into the actual time give the better understanding about the relation between time interval and pricing strategy (Figure 6 and Figure 7).

Fig. 6 Capacity Restraint Approach (with actual time)

Real movement $\longrightarrow$ Capacity restraint price $\longrightarrow$ Design Capacity

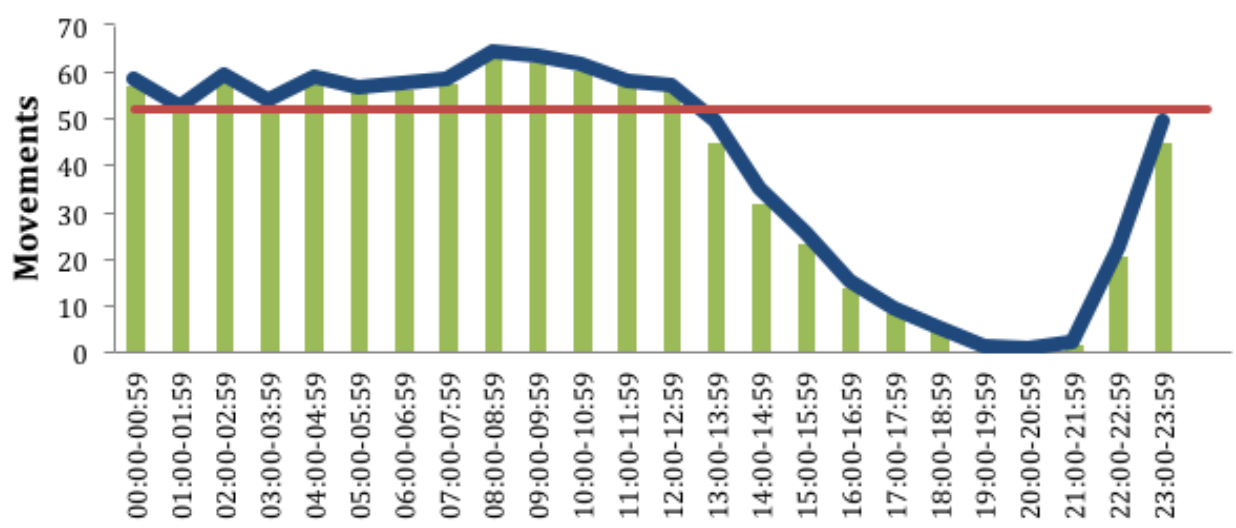

Time Interval

Fig. 7 Balanced Demand Approach (with actual time)

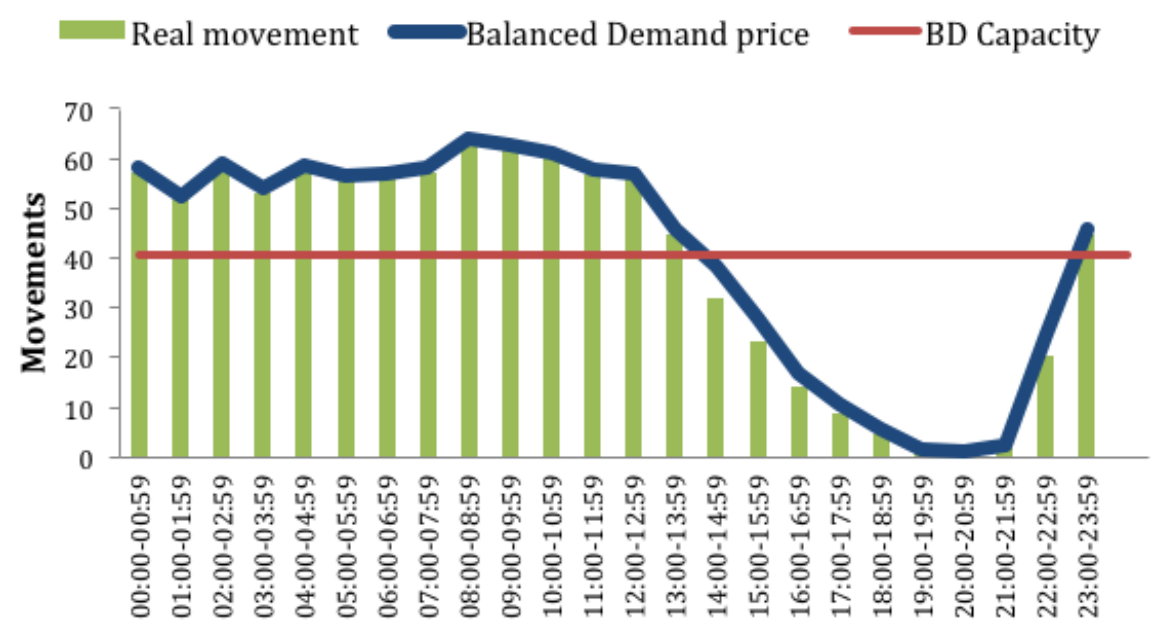

Time Interval 


\section{IMPLEMENTATION CHALLENGES}

There are several challenges and problems to be solved for the disincentive strategy can be properly implemented and show its positive effects for the Soekarno-Hatta International airport and other airports in Indonesia.

The first challenge is to overcome the unique condition of Soekarno Hatta International airport. This airport serves both as the main international hub for Indonesia and also main hub for the domestic flights. Most domestic flights making Soekarno-Hatte airport as their main connection hub airport. Such condition causing huge number of short haul flights, dominating the allocation of slot in this airport especially between morning and early evening hours.

The second challenge is the improvement of coordination among stakeholders in slot time coordination and air transport operation. Currently there are several civil enclave airport in Indonesia which need some upgrade in the air traffic system and operational management due to the high air traffic freuecy of the respective airports. But due to its status as civil enclave there are some restriction for forther development. This challenges must be solved due to the position of Soekarno Hatta airport as main hub airport for domestic flights. Disruption of inappropriate operation from these airports may cause disruption on Soekarno Hatta operation.

Third challenge is related to the nature of slot allocation system in which the slot capacity of the airport is the result of interrelation among air traffic capacity, runway capacity and the apron capacity. Currently Soekarno-Hatta Airport facing acute problem to increase its apron capacity. The problem worsened by the fact that most airline making Soekarno-Hata airport as their base, causing sharp decline in apron capacity in the evening thus resulting disruption of operation during night time peak hour traffic. 


\section{POLICY RECOMMENDATIONS AND WAY FORWARD}

The above analyses and simulations have demonstrated that the current aircraft movement pattern have responded to the existing demand for air transport. In a demand responsive environment, it is clear that passenger prefer a certain time to depart and arrive in SHIA. This demand has been met by airlines by adjusting their timetable and airport usage. The peaking of air traffic and the statistical test of indifference arrival/departure pattern clearly indicate the presence of such phenomena.

The current slot allocation mechanism which is based on the first-come-first-served basis has not been able to cope with managing the existing demand from both the passengers and airlines. The results have indicated that during the peak time, the air traffic movement exceeded the design capacity, thus exposing the airport to a serious safety issue.

The research found that existing slot time allocation does not consider market mechanism, and thus creating an opportunity to regulate the slot time based on auction system. Despite the fact that airport slot allocation is indeed a complicated undertaking due to the network effect, regulating slot time in SHIA will generate the demand for reallocation of slot time in preceeding and subsequent airports. SHIA is the most important airport in Indonesia, and therefore managing the capacity of existing runways is critical for both SHIA air traffic safety and redistributing the air traffic to manage the air traffic demand to other Indonesian airports. Already there are concerns with other airports such as Surabaya (SUB) and Makassar (UPG) for managing their runway capacity and terminals.

Simulating slot time market value reveals that the auction system can generate substantial revenues to maintain and operate the slot time management system, and is able to encourage evenly distribution of aircraft departure time. This research is initial step toward educating policy makers and airport authorities in Indonesia that the economics of air space is present in the national airport markets. The estimated value of the auction can be tested further with various instruments. The next step for the authority is to estimate the airspace value that can be labelled in each time interval, and therefore the government will be able to estimate the economic value of one of their national resources, time.

The simulation shows that in the event of the slot pricing and auction to be implemented in Soekarno-Hatta airport, the airlines that are willing to use slot time at the most demanded time interval should pay an additional $6.57 \%$ (CR approach) from total revenue gained by the government from slot sector and $6.55 \%$ (DB approach). It is to be rememberred that the current 
regulation does not generate revenue from the slot allocating process therefore further research is needed to calculate the potential revenue of slot allocation process.

The government must be able to distribute the air traffic burden especially thee domestic flights from the Soekarno Hatta International airport. Better coordination among the stakeholders also needed to better spread the demand for slot time especially for flights to eatern part of Indonesia. Upgrade of the existing airport especially for their apron and terminal capacity might be needed to tackle the slot capacity limitation problem. Development of new airport can also be considered especially for area which the airport can no longer be further upgraded or developed. 


\section{REFERENCES}

- $\quad$ J. Brueckner, "Slot-based approaches to airport congestion management," 2008.

- T. Department of the environment transport and the regions, "Auctioning airport slots Executive Summary," 2001.

- $\quad$ D. Starkie, T. Bass, and B. Humphreys, A market in airport slots. 2003.

- R. P. Lorenzo Castelli , Paola Pellegrini, "Airport slot allocation in Europe: economic efficiency and fairness," 2010.

- $\quad$ D. G. of Civil Aviation, "KP 280 Year 2015: Slot Time Management Guidelines." 2015.

- $\quad$ T. a. Weber, "Price Theory in Economics," Retrieved May, 2008.

- D. R. Polsby, D. R. Polsbyt, and B. Mitchell, "Airport Pricing of Aircraft Takeoff and Landing

Slots: An Economic Critique of Federal Regulatory Policy Airport Pricing of Aircraft Takeoff and Landing Slots: An Economic Critique of Federal Regulatory Policy," vol. 89, no. 3, 2001.

- A. Anggorosesar and R. Wijaya, "Potensi Pasar Sekunder Spektrum Frekuensi Radio di Indonesia The Potential of Secondary Market for Radio Frequency Spectrum in Indonesia," pp. 319334, 2013.

- M. of Communication and InformationTechnology, "PM Num 4 Year 2006: Auction Procedures for $2.1 \mathrm{GHz}$ Frequency on IMT-2000 Operation." 2009.

- P. Republic of Indonesia, "PP Num 7 Year 2009: Tariff and Types of State Non-Tax Revenues on Communication and Information Technology Department." 2009.

- $\quad$ P. Republic of Indonesia, "PP Num 76 Year 2010: Amendment of PP Num 7 Year 2009 Tariff and Types of State Non-Tax Revenues on Communication and Information Technology Department." 2010.

- M. of Communication and InformationTechnology, "PM Num 24 Year 2010: Third Amendment of PM Num 19 Year 2005 Tariff Guidelines on State Non-Tax Revenue from BHP of Radio Frequency." .

- $\quad$ M. of Communication and InformationTechnology, "PM Num 19 Year 2005: Tariff Guidelines for State Non-Tax Revenues from BHP of Radio Frequency." 2005. 